\title{
A inclusão escolar de alunos com deficiência mental: uma proposta de intervenção do terapeuta ocupacional no cotidiano escolar
}

\author{
The school inclusion for mental disorder students: \\ an intervention propose for the occupational \\ therapist in the school context
}

\author{
Andréa Perosa Saigh JURDI ${ }^{1,2}$ \\ Maria Lúcia Toledo de Moraes AMIRALIAN ${ }^{3,4}$
}

\begin{abstract}
Resumo
Parte-se do princípio de que, apesar da legislação existente em relação à inclusão escolar de alunos com deficiência mental, ainda ocorre sua exclusão nas relações cotidianas que se estabelecem na escola. O objetivo desta pesquisa foi compreender como a atividade proposta pela terapia ocupacional poderia interferir e modificar as relações estabelecidas em relação aos alunos com deficiência mental no ambiente escolar. Por meio do relato de uma experiência de intervenção realizada por estagiários de Terapia Ocupacional no horário de recreio de uma escola estadual de ensino fundamental da cidade de São Paulo, procuramos verificar se a atividade proposta - a atividade lúdica - provocaria possibilidades de encontro entre os alunos da classe especial e os outros alunos, propondo mudanças no processo de inserção escolar dos alunos com deficiência mental. A análise qualitativa da intervenção realizada vem apontar as dificuldades que o ambiente escolar apresenta ao estabelecer relações cotidianas de qualidade com o aluno com deficiência mental. Permeada por preconceitos e desconhecimento, as relações que se desenrolam no ambiente escolar reforçam, para o aluno com deficiência, o papel cristalizado no insucesso e no fracasso escolar, impossibilitando-o de ressignificar sua ação como indivíduo criativo, perpetuando um padrão de relacionamento que impede o processo de uma real inclusão escolar.
\end{abstract}

Palavras-chave: deficiência mental; inclusão escolar; terapia ocupacional; Winnicott.

\begin{abstract}
This paperconsiders that, besides the school inclusion law that regards handicapped students, these students have faced exclusion on their daily school relations yet. This study aimed to comprehend how influent was the activity proposed by Occupational Therapy in order to modify the established relations about these students in the school environment. Through the Occupational Therapy Trainees'report of an intervention experiment, that was conducted during the break time in an elementary public school in São Paulo city, this study also intended to verify if the proposed activity (the joke) was able to provoke the special and non-special students meeting, impelling gathering possibilities

\section{V}

1 Doutoranda em Psicologia Escolar e do Desenvolvimento Humano, Programa de Pós-Graduação em Psicologia, Instituto de Psicologia, Universidade de São Paulo. Av. Prof. Mello Moraes, 1721, Cidade Universitária, 05508-900, São Paulo, SP, Brasil. Correspondência para/Correspondence to: A.P.S. JURDI. E-mail: <andreajurdi@estadao.com.br>.

2 Membro do Laboratório Interunidades de Estudos sobre as Deficiências, Instituto de Psicologia, Universidade de São Paulo. São Paulo, SP, Brasil.

3 Professora Doutora, Instituto de Psicologia, Universidade de São Paulo. São Paulo, SP, Brasil.

4 Coordenadora do Laboratório Interunidades de Estudos sobre as Deficiências, Instituto de Psicologia, Universidade de São Paulo.
\end{abstract}


among students ( special needy or not), providing the school inclusion process for the mental handicapped students. This intervention qualitative analysis has pointed out to the school environment difficulties in establishing daily relations to the mental handicapped students. The school relations reinforce the school failure to the mental handicapped students, and unable them to give their creative action a new meaning, that keeps the relation pattern and blocks up the real school inclusion process.

Key words: mental retardation; school inclusion; occupational therapy; Winnicott.

Este artigo tem por objetivo discutir a inclusão escolar de alunos com deficiência a partir de uma intervenção no campo da Terapia Ocupacional em uma escola estadual de ensino fundamental da cidade de São Paulo.

As dificuldades que emergiram do cotidiano escolar nos mostraram que o tema da inclusão escolar ainda permanece como um problema a ser resolvido pelas escolas e pela sociedade.

O desconhecimento e as dificuldades que as escolas enfrentam ao lidar com alunos com dificuldades ainda são grandes. Apesar da intensificação das discussões a respeito desse tema, das leis federais, estaduais e municipais que trazem regulamentações à instalação desses processos de inclusão, ainda encontramos, no cotidiano escolar, nas práticas escolares, inúmeras dificuldades e questões que devem ser resolvidas e esclarecidas (Bueno, 1999; Kupfer et al., 2000; Mazzotta \& Sousa, 2000; Mittler, 2003).

Para a criança com deficiência, a possibilidade de acesso à escolarização traz ganhos inestimáveis. Até pouco tempo, uma parcela mínima dessa população tinha acesso aos bancos escolares e sempre a via de acesso eram as classes especiais ou escolas de ensino especializado, revelando que a relação entre deficiência e ensino especial ainda fazia parte de uma concepção na qual a condição de deficiente por si só definiria a conveniência e a necessidade desse atendimento especializado.

Atualmente, percebemos que essa concepção permanece impregnada nas práticas escolares, provocando ações excludentes dentro dos muros escolares. Nos agenciamentos que a escola provoca, percebemos que o aluno com deficiência mental ainda mantém o status de quem é diferente. O fracasso escolar o acompanha e o preconceito assume sua forma mais vil: a exclusão.

É necessária a transformação do espaço escolar a fim de trazer novos olhares para a deficiência. Não basta colocar o aluno portão adentro da escola, delegando-lhe um espaço físico dentro de sala de aula. É preciso que a escola, como instituição, viabilize formas de atendimento a essa população. É importante ressaltarmos que esses alunos têm não apenas o direito à educação, mas, também, têm o direito às oportunidades educacionais e isso implica atender, nas instituições escolares, a extensa gama de diferenças individuais existentes entre os educandos.

O ambiente escolar apresenta um estímulo à competitividade, à negação das diferenças e uma tendência a valorizar a homogeneidade, enfim, a escola requisita o aluno ideal e realiza suas ações para atender a esse aluno idealizado. Não há espaço para ser diferente e único, e para estabelecer um diálogo com a diversidade. Ao falarmos de um sistema de ensino inclusivo, precisamos falar de uma mudança de comportamento, de atitudes, valores e conceitos.

Ao adentrarmos no campo da educação, percebíamos que as leis não traziam para o cotidiano escolar apenas crianças com dificuldade em aprender o que a escola gostaria de ensinar, mas traziam crianças carregadas de uma história de exclusão e preconceitos, submetidas a relações de submissão permeadas por estereótipos.

Ao mesmo tempo, a entrada na escola nos ofereceu a possibilidade de transformações, quando dirigentes, professores e coordenadores nos solicitaram auxílio e soluções para as ações do cotidiano escolar que os ajudassem a pensar sobre essa população.

Temos as leis, mas faltam intervenções que tragam para o cotidiano escolar um outro olhar para o aluno com deficiência, suas possibilidades e singularidades, intervenções que instaurem as diferenças e não salientem as desigualdades.

A prática da Terapia Ocupacional com a população com deficiência mental vem nos mostrando que, apesar de haver um prejuízo intelectual, há, em contrapartida, a possibilidade de construção de um 
cotidiano que se estabeleça através dos significados e desejos. As habilidades que emergem do desejo de realizar do indivíduo, obriga-o a ocupar um outro papel na comunidade.

As possibilidades de ser e de fazer do indivíduo nos mostram a potência da atividade como possibilidade de transformação e criação, uma vez que essa atividade precisa estar impregnada de desejo, de sentido ou de um objetivo que justifique um movimento ou uma ação sobre o mundo. Nessa perspectiva, o indivíduo com deficiência deve ser visto não como incapaz, mas, sim, como um indivíduo com especificidades, e a deficiência, vista como condição e não como doença.

Justificando esses princípios, aproximamo-nos do referencial teórico winnicottiano na medida em que essa teoria nos fornece subsídios para pensarmos a articulação entre indivíduo e ambiente. Essa teoria nos propõe uma determinada visão de homem no mundo, sua subjetividade e conseqüente relação com o ambiente, produzindo uma importante discussão sobre a constituição do indivíduo e sua formação.

É a partir da compreensão da integração do indivíduo e do papel do ambiente no processo de amadurecimento que abordaremos o papel da escola e a intervenção realizada.

\section{A Teoria Winnicottiana}

Para Winnicott (1988), um estudioso da natureza humana, saúde significa integração, isto é, na saúde o indivíduo encontra-se integrado, habitando o próprio corpo e sentindo que o mundo é real. Em sua visão de homem, o autor acredita que fatores ambientais e pessoais devem ser considerados, priorizando a constituição da experiência a partir da relação com o outro. Concebe a criança somato e psiquicamente em constante troca com o ambiente, entendendo que ela se desenvolve e amadurece no encontro com o outro humano.

A reflexão sobre essa teoria ajuda-nos a pensar sobre a questão do que é herdado e ou adquirido no indivíduo, sobre o desenvolvimento de seu psiquismo e sobre as implicações dessas discussões no meio educacional. Todo ser humano é dotado de uma tendência inata ao amadurecimento e à integração em uma unidade, sendo essa sua herança mais importante. Assim, o principal da hereditariedade é a tendência inerente do indivíduo a crescer, se integrar, se relacionar com objetos e amadurecer. Mas apenas a tendência é inata, não os caminhos pelos quais ela se realiza, o que significa que a tendência ao amadurecimento pode ou não vir a se realizar. Existir é sempre uma conquista, um eterno vir a ser, que diz respeito não ao biológico ou ao psíquico, mas ao que é especificamente pessoal: o sentimento de ser, de existir em um mundo real.

A contribuição de Winnicott ao estudo da natureza humana é o detalhamento sobre o que se passa com o bebê nos estágios iniciais do amadurecimento, que se inicia em algum momento após a concepção. Esse detalhamento nos permite abordar a questão das deficiências a partir de um novo olhar.

Amiralian (2003) ressalta que as propostas de Winnicott trouxeram contribuições significativas sobre a compreensão do desenvolvimento daqueles que apresentam alguma deficiência física ou funcional. Segundo a autora, Winnicott, ao propor a organização e desenvolvimento do psiquismo a partir da elaboração imaginativa das funções somáticas, nos leva a considerar a importância dos déficits e lesões orgânicas na constituição do psiquismo.

A deficiência, a partir desse ponto de vista, passa a ser concebida como parte integrante do psiquismo desse indivíduo e deve ser considerada nesse contexto. Sendo uma condição constituinte do indivíduo que a possui, ele terá experiências somáticas peculiares e seu psiquismo terá como base essas vivências. Desse modo, aqueles que possuem alterações no tecido, ou no funcionamento cerebral desde o nascimento, terão seu psiquismo construído a partir dessa condição (Amiralian, 2003).

Temos, portanto, uma proposta teórica que nos fala de um desenvolvimento saudável que possibilita ao indivíduo crescer e amadurecer de acordo com seu aparato biológico que, na interação com o ambiente, terá como função oferecer condições necessárias e suficientes que favoreçam o amadurecimento das crianças com deficiência.

Ao falar sobre o processo de amadurecimento, Winnicott (1988) refere que para o bebê tornar-se real é preciso que haja um ambiente que lhe dê sustentação 
e facilite os processos de amadurecimento, ressaltando que isso só poderá ocorrer em um ambiente humano de confiabilidade. O ambiente perfeito é o que se adapta ativamente às necessidades do bebê que acabou de nascer. Nesse estágio, o bom ambiente é o ambiente físico, com a criança no útero ou sendo segurada e cuidada de modo geral.

A dependência do bebê, nesse estágio, remete-o a necessitar do ambiente de um modo absoluto; e esse, ao adaptar-se suficientemente bem às necessidades do bebê, fornece condições para que ele caminhe em direção à dependência relativa e desta para a independência que, para o autor, jamais será total.

O bebê humano não existe separadamente da mãe e sua tendência inata ao amadurecimento refere-se à sua tarefa de se tornar uma unidade. A mãe, chamada por Winnicott de mãe devotada comum ou suficientemente boa, oferece-lhe a sustentação física e psíquica necessárias à sua integração, permitindo que seu bebê seja capaz de sentir-se como um todo, de modo que, a partir de suas peculiaridades, possa se constituir como indivíduo. Além de oferecer condições para que seu bebê se integre, a mãe tem a importante função de apresentar o mundo ao seu filho, o mundo dos objetos conhecidos, oferecendo-Ihe possibilidades de experiências.

O ambiente atua como facilitador no processo de amadurecimento humano, e só é considerado facilitador quando oferece condições para o crescimento do indivíduo em direção à saúde, não obstrui o desenvolvimento e nem tenta forçar sua ocorrência. Se o ambiente falha, em uma proporção superior às possibilidades que o indivíduo suporte, pode ser gerada uma instabilidade que pode fazê-lo adoecer.

Freller (1999) refere que na teoria winnicottiana ¿ há dois movimentos fundamentais para o ambiente c facilitar o encontro do indivíduo com os objetos oxternos. O primeiro refere-se às funções exercidas pelo 3 meio, que possibilitam à criança construir um espaço > em que pode experimentar, brincar e interagir com determinada cultura. A segunda função importante do ambiente é que esse forneça material cultural nas fases apropriadas do desenvolvimento da criança, de acordo com sua capacidade, idade e necessidades.

Portanto, o ambiente tem um papel fundamental na constituição e no processo de desenvol- vimento do indivíduo, pois à medida que a criança cresce, o conteúdo de sua vida pessoal não se restringe apenas a ela. Em seu processo evolutivo, a criança afrouxa os laços da dependência familiar e passa a integrar a sociedade global, apropriando-se da herança cultural, devendo o ambiente provê-la nesse sentido.

É evidente que à medida que a criança cresce, o conteúdo de sua vida pessoal não fica só restrito a ela. O self passa a ser, cada vez mais, moldado pela influência do ambiente (Winnicott, 1983, p.93).

Temos, portanto, uma proposta teórica que nos fala de um desenvolvimento saudável que possibilita ao indivíduo crescer e amadurecer de acordo com seu aparato biológico e um ambiente que terá como função oferecer condições necessárias para a ocorrência desse amadurecimento.

Nessa teoria, a entrada na escola é conseqüência de um caminho gradual que parte da relação do indivíduo com a mãe e é seguida pela relação com a família, com a escola e com a sociedade mais ampla. 0 estudo das funções ambientais posteriores devem ser pensado, levando-se em conta o papel da mãe. Isto é, Winnicott (1999) nos fala de um certo modelo de relação em que as coisas são sempre uma questão de crescimento e desenvolvimento.

Vocês vão perceber que as coisas para mim são sempre uma questão de crescimento e desenvolvimento. Nunca penso no estado de uma pessoa aqui e agora a não ser em relação ao meio ambiente e ao crescimento dela desde sua concepção até a época do nascimento (Winnicott,1999, p.139).

A escola, como primeiro ambiente fora do âmbito familiar, recepciona e coloca o futuro adulto na esfera das relações sociais. Por isso mesmo, sua importância nas primeiras experiências vividas no seu interior será decisiva para a construção do modo desse indivíduo se colocar no mundo, nas relações com o outro, frente ao conhecimento e ao ato criativo (Rosa, 1996).

Para que haja a garantia da continuidade existencial da criança, o ambiente adequado contribui, sustentando a relação dialética que o indivíduo estabelece com o mundo, articulando realidade interna e externa, nos vários processos transicionais experimentados ao longo de seu processo de desenvolvimento. 
Na educação, o processo ensino-aprendizagem ocorre na mesma área em que o brincar acontece - o espaço potencial - assim como os processos de socialização que intermediados pelos fenômenos transicionais facilitam a passagem do mundo familiar para a cultura mais ampla.

A escola é um espaço aberto, um espaço de criação, um lugar privilegiado de trânsito entre criação e tradição. Porém esse espaço deve ser compreendido não como espaço físico, mas um espaço de possibilidades que se estabelecem a dois: entre professor e aluno.

No processo de amadurecimento da criança com deficiência mental o ambiente é, muitas vezes, repetidamente insuficiente, obrigando-a a reagir, substituindo seu gesto espontâneo pela submissão, adaptação e imitação, indo contra sua própria natureza. No desenvolvimento saudável o indivíduo cria o mundo, não se adapta a ele. A adaptação não é senão o falso self, desenvolvido através das falhas ambientais, aparecendo como defesa do verdadeiro self, que leva a criança a ficar submetida ao outro."O falso self se desenvolve sobre uma base de submissão e se relaciona com as exigências da realidade externa de forma passiva" (Winnicott, 1988, p.128).

Ao nos determos no campo da educação, deparamo-nos com o aspecto imperativo que ela imprime ao aluno com deficiência mental, oferecendoIhe, na maioria das vezes, o lugar do não saber, da falência do ideal. Na interação com o ambiente escolar, as crianças com deficiência mental, muitas vezes, são atravessadas por relacionamentos que as desqualificam em seu fazer e as impelem à submissão e à adaptação ao ambiente. $\mathrm{O}$ aspecto imperativo da educação, no campo da deficiência, é particularmente grave e colabora com o impedimento do processo de desenvolvimento dessas crianças, impedindo o indivíduo de manifestar seu verdadeiro self.

Porque, para o deficiente mental, dizer-lhe tudo o que tem que aprender, fazer e seus modos não é somente suprimir provisoriamente a sua criatividade .... Equivale, o que é ainda mais grave, a dizer-lhe que dele não se espera que saiba nada por si mesmo, ou que o deduza ou que o invente. Ou seja, repetir o que lhe vem sendo dito em sua casa ou no mundo externo, suprimindo a esperança, se é que ainda the restava alguma, de que na escola lhe reconheçam outra condição que a de nulidade absoluta (Jerusalinsky et al., 1999, p.111).

Ao participarmos de processos de inclusão escolar, percebemos que ao inserirmos essa criança na escola não estamos, obrigatoriamente, incluindo-a. Muitas vezes, no cotidiano escolar, ela vivencia situações que a excluem das relações que se desenvolvem nesse cotidiano. O resultado, em geral, é o afastamento, o não compartilhar e o sentimento de estranheza que a acompanha. Assim, a escola em sua prática acaba por cristalizar a marca de deficiente, contribuindo para sua constituição como indivíduo deficiente.

Nesse sentido, faz-se necessário pensar em intervenções que proporcionem à criança realizar seu desenvolvimento escolar/cognitivo, para que possa atuar no mundo de forma singular e criativa, possibilitando a emergência de sua subjetividade. É papel da escola participar da ampliação e enriquecimento do espaço potencial, oferecendo material cultural de forma que o aluno possa se apropriar dele de forma criativa e singular, preservando sua identidade pessoal e grupal.

O campo da Terapia Ocupacional oferece-nos a compreensão de que a atividade pode nos trazer respostas mais concretas a esse respeito, respaldando intervenções que tragam para o cotidiano escolar um outro olhar para o aluno com deficiência mental, suas possibilidades e singularidades, intervenções que instaurem as diferenças e não as imprimam como valores.

Nesse sentido, a potência da atividade como recurso utilizado para intervir nas relações cotidianas fundadas na exclusão e preconceito oferece um outro olhar para o fazer do indivíduo. Sua capacidade de criar, fazer, estabelecer uma ação no mundo, tem sua origem na relação primordial com a mãe, e estende-se à vida adulta, sendo que o fazer criativo só poderá emergir se o indivíduo tiver uma relação com o ambiente sustentada na confiabilidade.

\section{Conhecendo o cotidiano escolar}

Como supervisora de estágio de alunos de quarto ano do curso de graduação de Terapia Ocupacional da Universidade de São Paulo (USP), abordamos o tema da inclusão escolar e compomos parcerias com diversas escolas da região, que requisitam nosso trabalho. 
Essa escola tem em seu quadro uma classe especial para alunos com deficiência mental e solicitou um trabalho em conjunto que os ajudasse a pensar sobre a terminalidade de alguns alunos da classe especial. O que fazer com os adolescentes que teriam que sair da escola após passarem anos na classe especial? Para onde os encaminhar? Antes de respondermos a essas questões começamos a freqüentar os espaços da escola em seus mais diferentes horários, conhecer o cotidiano e o lugar que ocupavam os alunos da classe especial dentro da escola.

Optamos por propor uma parceria com a escola direcionando nossa atenção para o cotidiano escolar e a rede de relações que se estrutura nesse cotidiano. Para autores como Ezpeletta e Rockwell (1989), um dos apoios iniciais para discutirmos a integração entre escola e aluno é a noção de vida cotidiana, o que fundamenta a opção metodológica e o corte empírico. Os autores afirmam que se aproximar da escola com a idéia de vida cotidiana significa algo mais que chegar e observar o que ali ocorre diariamente. Antes, é a orientação de uma certa busca e uma certa interpretação daquilo que pode ser observado na escola. Nesse sentido, o conceito de vida cotidiana delimita e recupera conjuntos de atividades caracteristicamente heterogêneas, empreendidas e articuladas por sujeitos individuais.

Fez-se necessário construir uma leitura da realidade encontrada que nos permitisse estabelecer parâmetros para uma determinada intervenção. A construção dessa leitura se deu a partir de encontros: com a infância, com os professores, com a deficiência. Ao entrar no cotidiano escolar e participar de vários momentos dessa rotina fez-se necessário definir alguns procedimentos para dar início à intervenção.

No dia-a-dia, a escola funciona em dois turnos: 总 das 7 às 12 horas e das 13 às 18 horas. A classe especial c encontrava-se apenas no período da tarde. Exceto no horário de recreio, os alunos da classe especial não $3 \quad$ tinham contato com os outros alunos da escola.

O primeiro procedimento refere-se à observação do cotidiano escolar. Nessa abordagem, a observação ocupa lugar privilegiado, pois é utilizada como principal método de investigação. Um roteiro de observação possibilitou o conhecimento da escola, seu cotidiano e dos próprios alunos, permitindo que o olhar fosse focado para alguns contextos como salas de aula, recreio, momentos de entrada e saída de alunos e atividades extra-sala. A sala de aula é o local privilegiado do ensino formal, onde as crianças passam o maior tempo em que permanecem na escola. No entanto, consideramos que não é o único espaço em que ocorre a aquisição do conhecimento. A observação da sala de aula, nesse estudo, teve por objetivo verificar a forma como os trabalhos escolares eram realizados, as relações sociais que se estabeleciam, o uso da atividade lúdica, não apenas como recurso pedagógico, mas como forma de expressão, criação e padrão de relacionamento.

A entrevista informal com os alunos durante o período de observação foi outro procedimento utilizado para que pudéssemos conhecer o repertório lúdico dos alunos e como eles concebiam as diferenças e os diferentes na escola, assim como a filmagem do recreio, que permitiu focar o olhar para as brincadeiras que ali aconteciam e delimitar as relações que ocorriam entre os alunos da classe especial e os alunos das classes regulares.

A observação e a compreensão do cotidiano escolar e seus atores deram-se por meio de encontros, que nos permitiram entender os fenômenos que lá aconteciam. Encontro com a infância, com os professores, com as pessoas com deficiência e o encontro no recreio, que nos possibilitou delimitar a intervenção.

No período de observação, encontramos crianças cuja bagagem cultural parecia, muitas vezes, ignorada e desprezada pelos educadores, transformando a história escolar em uma história sem pré-história e causando dificuldades nos alunos em se apropriarem de recursos utilizados pelos educadores. Em todas as salas, havia alunos com dificuldades básicas de alfabetização, pouca conversa ou trabalho em grupo e muita disciplina.

Quanto aos professores, as conversas e os contatos aconteciam nos horários que tinham para discutir planejamento e atividades de sala, chamando a atenção, durante conversas e reuniões, a descontinuidade família-escola, tendo a escola uma fala que culpabilizava a família pelos fracassos e dificuldades dos alunos. Além disso, havia um descontentamento por parte dos professores em relação a qualquer proposta de trabalho conjunto. Percebíamos que não queriam nos ouvir, mas, sim, queriam soluções rápidas para seus problemas. Esses professores pareciam destituídos de 
seu saber, pois, segundo a coordenadora, o planejamento sofria intervenções de outras instâncias. Destituídos de um saber que já não Ihe pertencia, mas que pertencia a outras áreas e instâncias, culminam por exercer um poder de controle sobre seus alunos. Ao se sentirem destituídos desse saber, os professores apenas repassavam um conhecimento. Não transformavam, não tinham prazer, não tinham o desejo de realizar, não brincavam. Invasivo e perseguidor, o ambiente não era satisfatório para que o professor pudesse exercer seu fazer de forma criativa e pessoal. $O$ ambiente que parecia se estabelecer na escola era um ambiente disciplinador e muito severo com a infância.

Nesse ambiente, o paradoxo de criar o que é encontrado no ambiente era eliminado pelo professor, que apresentava o objeto como externo, acabado, possibilidade única, sob seu controle e domínio. A criança não podia se apropriar e usar, mas apenas olhar, observar, copiar e imitar. Aluno e professor não criavam, ambos sofriam da mesma dificuldade na manifestação do si mesmo em um ambiente invasivo.

Na classe especial para alunos com deficiência mental, cuja faixa etária variava entre oito e dezoito anos, o encontro foi com o tédio, o desânimo, a mesmice. Uma atmosfera de repetição pairava no ar e paralisava professora e alunos na impotência e na impossibilidade. Tampouco nessa classe havia algo de lúdico ou criativo. A impossibilidade era o tom da conversa: "Não sei. Ele não consegue. Ele não faz. Ele não pode".

A professora encontrava-se fechada em sua própria classe, não participava das reuniões com os outros professores, nem seu planejamento era feito no mesmo período. Parecia estar excluída do resto da escola. Ao mesmo tempo, colocava-nos que seus alunos pareciam estar integrados ao resto da escola. Relatava-nos que um de seus objetivos era o encaminhamento de seus alunos para classes regulares, mas que suas tentativas foram frustradas. Poucos alunos conseguiram efetivamente permanecer nas classes regulares, mesmo tendo adquirido conhecimento para a continuidade do trabalho pedagógico. Alguns se recusavam a sair da classe especial, outros iam e voltavam. Para a professora parecia ser uma fatalidade; para a escola, a problematização desse fato não era importante, sendo mais fácil creditar o fracasso ao aluno e fazê-lo voltar para onde acreditavam que deveria ficar.
A observação no recreio nos deu a exata dimensão da antítese das salas de aula. Observar o recreio era observar uma explosão de risos, sons, contatos. Era a alegria e o sabor de estar solto e poder realizar algo seu, construindo as brincadeiras sem interferências de adultos. Por outro lado, o recreio reproduzia a exclusão anteriormente observada: os alunos da classe especial nunca brincavam com outras crianças; xingamentos e ofensas os perseguiam. A partir de uma experiência de jogo compartilhado durante o recreio, percebemos que esse poderia ser o espaço para intervir por meio do lúdico e favorecer outras relações, provocando mudanças em relações tão cristalizadas.

A escola pouco valorizava, ou priorizava, a possibilidade de exploração do espaço potencial, seja em cada sujeito, seja na relação com o outro. Espaço esse que Winnicott (1975) coloca como o lugar do jogo, da criatividade e da experiência cultural. Em seu lugar priorizava-se uma relação de submissão e adaptação ao ambiente escolar.

Entendemos que, nesse espaço, poderia ser iniciada uma experiência que provocasse o desmonte das ações de exclusão que a escola vivia. Através da intervenção com os alunos, delimitada pelo espaço e pelo tempo do recreio, compreendemos que as relações poderiam se modificar por meio de um fazer coletivo que trouxesse as diferenças como fundamentais para as relações compartilhadas que se estabeleciam no dia-a-dia. Pois, nessa escola, os alunos com deficiência mental estavam sim inseridos, mas a partir do status que os definia a partir do não saber, do louco, do doente.

Em nossa sociedade, a competição e o individualismo são a tônica das relações. A escola, reproduzindo as relações sociais mais amplas, não se diferencia disso e marca a diferença entre o tempo para brincar e o tempo para aprender, a diferença entre quem aprende e quem não aprende, entre o bom e o mau.

As características que a atividade lúdica traz consigo, como a possibilidade de estimular a autonomia, de ter um caráter livre e criativo, de alterar papéis, fazem com que seja possível reverter as relações sociais que se estabelecem na instituição.

Portanto, partimos do princípio de que a interação social entre pessoas com deficiência e sem deficiência é benéfica para ambas as partes. A atividade lúdica possibilita outras formas de relação e de 
estabelecer e de auxiliar uma interação mais positiva.

Ao propormos uma intervenção no horário de recreio, compreendemos que a atividade proposta, a atividade lúdica, poderia provocar possibilidades de encontro entre todos os alunos da escola - os alunos da classe especial e os alunos das classes regulares -, propondo mudanças no ambiente escolar.

\section{Relato da intervenção}

Ainda durante o processo de conhecimento do cotidiano escolar a observação do recreio foi fundamental para definirmos o ponto inicial da intervenção, que passa a acontecer uma vez por semana durante quatro meses, por duas alunas do quarto ano do curso de graduação em Terapia Ocupacional da Universidade de São Paulo.

No recreio, em um primeiro momento, há um movimento caótico. Crianças correndo de um lado para outro, parecendo sem destino. Mas, observando melhor, esse movimento se traduz em uma explosão de brincadeiras, gritos, brigas, contatos. Percebemos grupos de crianças organizados em suas brincadeiras, próprias da idade, com repertórios lúdicos, próprios da cultura e da faixa etária. Brincavam de pega-pega, cinco marias, bolinhas de gude, figurinhas, polícia e bandido, dentre outras. O excerto extraído do relatório de uma das estagiárias traz elementos importantes sobre o movimento e as atividades que ocorrem no horário de recreio:

no decorrer das observações, fui transformando meu olhar à medida que conhecia o espaço e o brincar daquelas crianças. Na primeira observação, toda movimentação parecia-me caótica, demorei a identificar alguma brincadeira. Via muito futebol, crianças correndo de um lado para outro (inicialmente não entendia essa movimentação, essa agitação). Após algumas observações e processual mergulho na cultura lúdica daquelas crianças, as ações enchiam-se de significados e faziam-me entender que naquele caos da primeira impressão estava o pega-pega, menino que pega menina, menina que pega menino, o escondeesconde, a garrafa de água quevirava bola, o subire descer o alambrado, uma amarelinha desenhada no chão jogada apenas pormeninos. Vejo um pião, uma boneca, uma bolinha de pingue-pongue: brinquedos trazidos de casa. Percebo também uma violência corporal vinculada à brincadeira: chutes, empurrões, puxões. A todo recreio presenciava brigas e me desesperava com medo que alguém se machucasse, mas depois percebia que não eram brigas, eram brincadeiras e não as via inicialmente dessa forma porque talvez não tivesse me apropriado dessa cultura lúdica.

Nesse movimento, os alunos da classe especial não se organizavam para as brincadeiras, não eram convidados e pareciam não se interessar por elas; os adolescentes, possivelmente por não compartilharem os mesmos interesses, e as crianças, por não conseguirem entrar nos grupos já formados.

Durante o recreio, que tinha a duração de 20 minutos, as crianças deveriam se alimentar e brincar. Assim, decidiu-se que a intervenção ocorreria uma vez por semana.

Foi feito um levantamento com todos os alunos que participavam do recreio para conhecer o seu repertório lúdico. As atividades propostas, portanto, corresponderam a esse repertório. As estagiárias passavam nas classes, no dia determinado, convidando-os a participarem da brincadeira. As brincadeiras mais citadas e conhecidas eram: futebol, lutinha, pega-pega, queimada.

Logo se percebeu que os alunos da classe especial detinham o mesmo repertório lúdico dos alunos das classes regulares, ou seja, as brincadeiras eram comuns. Portanto, não era por desconhecimento que não participavam das brincadeiras organizadas por esses. Alguns adolescentes não tinham interesse em participar de algumas brincadeiras que chamavam de "brincadeira de criancinha". Entendíamos, portanto, essa escolha como uma vontade própria e não imposta pelo grupo.

Nesse processo, os alunos da classe especial começaram a fazer parte das brincadeiras e dos jogos propostos pelas estagiárias. De modo geral, os alunos mostraram-se receptivos às brincadeiras propostas e à participação dos alunos da classe especial, apenas não permitindo que as regras do jogo se alterassem de tal modo que o descaracterizasse (como aconteceu em um jogo de queimada em que três bolas estavam em jogo, descaracterizando-o completamente e levando à frustração seus jogadores). 
Em contrapartida, num jogo chamado "alerta", um aluno da classe especial modificou as regras e o jogo tornou-se mais divertido e dinâmico; D. não respeitou as regras iniciais, mas essa não incorporação das regras foi absorvida pelo grupo. D. provocou um novo jogo, um novo movimento, uma nova ação e esse novo jogar foi incorporado pelo grupo. Esse significado não foi uma ruptura com o jogo - como com a colocação de mais bolas na queimada -, ocorreu uma transformação, que foi sendo percebida durante a movimentação no jogo, e que tinha o consentimento coletivo.

Quando brincamos de "corre cotia", alguns alunos da classe especial tinham um ritmo mais lento para a corrida, e para perceberem que era sua vez, alguns precisavam de ajuda e dicas. Mas o grupo conseguiu jogar sem que apontassem quem eram os melhores.

Os jogos compartilhados trouxeram uma outra tônica ao recreio e à vivência dessas crianças. Puderam conhecer uma outra forma de brincar, que não estava centrada na competição, na exclusão e na desigualdade.

No recreio, as diferenças expressas continuaram a existir e, através da atividade lúdica, puderam ser percebidas não como algo menor ou ruim, mas como constituintes de todos nós, como pessoas únicas e diferentes.

\section{Análise}

A análise dessa intervenção está inscrita e é decorrente do papel que o ambiente escolar desempenha em relação aos alunos com deficiência mental. Portanto, não pode estar separada ou desconexa da análise do ambiente escolar.

Nesse contexto específico, a exclusão intramuros, que permeava as relações cotidianas, não se restringia apenas aos alunos com deficiência, mas abrangia todos os alunos sem distinção, desde que não se mostrassem aptos a ocuparem o lugar do aluno idealizado pela escola.

Para Winnicott (1983), a criança, em seu processo evolutivo, afrouxa os laços da dependência familiar e passa a integrar a sociedade global e a apropriar-se da herança cultural, devendo o ambiente provê-la nesse sentido. Mas, quando o ambiente é repetidamente insuficiente e invasivo, obriga essa criança a reagir e substituir seu gesto espontâneo pela submissão, adaptação e imitação.

Em sua relação com o ambiente, percebe-se que as crianças com deficiência somam fissuras de descontinuidade, marcando seu processo evolutivo, deixando marcas em sua personalidade e na forma como vão se estruturando como sujeitos sociais e culturais.

A escola como ambiente deve sustentar a continuidade do processo evolutivo de cada aluno, pois as experiências vividas na escola se somam e ressignificam experiências de histórias passadas da criança, influenciando na sua auto-expressão e interação com a cultura.

Ao priorizar a adaptação e a submissão por meio de certos modelos de educação e práticas pedagógicas, que recorrem a repetições incansáveis como propostas de recursos especializados, a escola pauta suas relações com os alunos com deficiência mental pela falta e não pela manifestação do si mesmo. Sob esse ponto de vista, a escola não destaca o papel da criação na relação do indivíduo com o mundo compartilhado e com a cultura mais ampla. Mas como uma mãe que não consegue criar ambiente para a ilusão e também para a desilusão, prende a criança com deficiência em um ambiente sem criatividade, sem contato com os objetos do mundo externo.

A escola, embora não seja o único espaço, é o lugar favorável, por excelência, para promover o aprendizado formal. Porém, o papel que a escola desempenha não se restringe apenas aos processos formais de ensino-aprendizagem, mas se constitui um importante espaço de trocas, agenciamentos, de transmissão de valores sociais e culturais, e, portanto, é um espaço onde a desmistificação da deficiência pode ocorrer de forma concreta.

Durante nossa intervenção no recreio percebemos que os alunos das classes regulares verbalizavam que não brincavam com os alunos da classe especial por que eles não sabiam ou não conseguiriam brincar, denotando uma atitude fundada em um desconhecimento a respeito da deficiência mental e do indivíduo que a tem.

Esse tipo de atitude não parecia incomodar ao corpo docente, técnico e funcionários da escola que, de 
certa forma, através de algumas atitudes, chegavam a reforçar e a reafirmar o papel do aluno incapaz ou doente. Ao delegarem um local exclusivo na escola para os alunos da classe especial - como, por exemplo, no momento de entrada dos alunos na escola -, marcavam uma diferença que levava à exclusão. Ao comparar os outros alunos com os alunos da classe especial, por meio de palavras depreciativas, localizavam nesses alunos a falência do ideal.

Durante o processo de intervenção no recreio, oferecer outros modelos de relação - como convidar os alunos da classe especial, esperar o momento de cada um, não nomear negativamente suas ações e favorecer o acesso de todos às brincadeiras - trouxe um outro contexto ao recreio. Começou a se estabelecer um outro padrão de relacionamento entre os alunos, que enfatizava não apenas a cooperação, mas também respeitava as intervenções dos alunos, seus pedidos e o que traziam de conhecimento a respeito das brincadeiras propostas.

O espaço e o tempo do recreio foram o palco de uma nova experiência que provocou o desmonte das ações de exclusão em que essa escola vivia. Por meio da intervenção com os alunos, entendemos que as relações poderiam se modificar a partir de um fazer coletivo que trouxesse as diferenças como fundamentais para as ações compartilhadas que se estabelecem no dia-a-dia. As características que a atividade lúdica traz consigo, como a possibilidade de estimular a autonomia, de ter um caráter livre e criativo, de alterar papéis, fazem com que seja possível reverter as relações sociais que se estabelecem na instituição escolar, pensando como a ludicidade, presente em cada um de nós, pode ser um veículo transformador de

: ações que favoreça a construção de uma cultura mais ¿ solidária. como qualidade de relação que os indivíduos estabelecem com os objetos do mundo externo e a conseqüente apropriação da experiência cultural. Como atividade humana, abre possibilidades para um campo onde as subjetividades se encontram com os elementos da realidade externa, possibilitando uma experiência criativa do conhecimento. Para Winnicott (1975), a saúde inclui a capacidade de brincar e essa atividade é considerada o protótipo do viver criativo. Atividade sustentada pela ilusão básica refere-se também à liberdade de transitar pelos vários mundos que são criados no decorrer do amadurecimento.

Mas, para que se pudesse estabelecer um outro modelo de relação, os alunos da classe especial teriam que assumir, também, esse outro modelo. Desempenhar um outro papel que não o de deficiente, tão conhecido pela escola, torna-se uma tarefa difícil.

Durante a intervenção, os alunos da classe especial demonstraram dificuldade em sair de um modelo de relação já conhecido, mas as atividades lúdicas, aliadas a uma outra atitude, propiciaram ações mais criativas nesse sentido, como a possibilidade de um dos alunos da classe especial modificar as regras de uma brincadeira e de essa ser aceita pelo grupo todo. As transformações percebidas nessas atividades foram nítidas quando, ao final, percebemos mudanças no recreio em relação à participação dos alunos da classe especial, permanecendo junto às outras crianças, compartilhando o mesmo jogo de forma mais ativa.

Ao não reproduzirmos o mesmo tipo de relação que a escola mantém com os alunos da classe especial, oferecemos a eles um outro lugar: o de sujeitos criadores da ação. Mas, percebemos o quão difícil é, para esses alunos, manterem-se nesse papel, pois, ao estabelecerem um outro padrão de relacionamento, precisam ocupar um outro lugar social e desempenhar um outro papel que não o já conhecido papel de "deficiente", acomodando-se nessa situação, já que muitas vezes, deixar de ser deficiente é deixar de ser. Como diz Jordão (2001, p.30): "perceber-se de forma diferente não é tarefa simples, o que está em jogo é sua própria identidade, pois muitas vezes deixar de ser deficiente, de ser incapaz é deixar de ser".

As atividades lúdicas realizadas no momento do recreio, baseadas em uma relação de confiabilidade, puderam trazer o germe de possíveis transformações nas relações cotidianas que se desenvolvem nessa escola. O espaço do recreio é rico em trocas e encontros. Várias experiências têm sido realizadas nesse espaço de brincadeiras, reforçando-o como espaço rico em trocas sociais. A sua utilização pode ser considerada um dos indicadores da real inclusão desses alunos na escola. 


\section{Considerações Finais}

O objetivo deste trabalho foi pensar de que forma a atividade lúdica poderia interferir e modificar relações estabelecidas no ambiente escolar e de que forma ela poderia auxiliar e compor os processos de inclusão escolar de alunos com deficiência mental.

$\mathrm{Na}$ teoria winnicottiana, o acontecimento humano depende da intervenção do ambiente, sendo que sua primeira função se dá por meio da facilitação que ocorre em três funções básicas: segurar, manejar e apresentar objetos, realizadas no momento certo, de forma adequada, respeitando e partindo das características e necessidades do indivíduo. Portanto, a atualização da tendência ao amadurecimento depende da facilitação ambiental e da não interrupção da continuidade desse processo, compreendendo-se que não existe indivíduo desvinculado de seu meio cultural. A segunda função importante do ambiente é fornecer material cultural relevante para uma determinada necessidade, nas fases apropriadas do desenvolvimento da criança, de acordo com sua capacidade e necessidade.

A escola deve desempenhar essas funções em relação ao seu aluno com deficiência mental: participar da instauração e ampliação do espaço potencial, apresentando materiais culturais relevantes, de forma que seu aluno possa se apropriar dos mesmos de forma criativa e singular.

Mas, ao longo do trabalho realizado, a escola se apresentou com um sistema educacional homogeneizador, que não concebe as diferenças, que, quando emergem, são vistas como distúrbios que ferem a harmonia positivista, precisando ser identificadas, rotuladas e segregadas.

Constatamos a grande dificuldade que a escola teve em ressignificar o papel que a pessoa com deficiência tem na sociedade. Essa dificuldade pareceu estar enraizada na concepção de que pessoas com deficiência mental possuem qualidades negativas, uma vez que o termo deficiência, no senso comum, nega a eficiência. A escola reportava-se às faltas e não às potencialidades individuais, reproduzindo atitudes e valores da sociedade mais ampla.

A visão que muitos pais, profissionais e educadores têm do aluno com deficiência mental, como um ser incapaz, infantil e dependente, sempre esteve presente nas atitudes que reforçam ainda mais essas características estigmatizantes, colocando-se como um dos entraves às propostas de sua inclusão no sistema regular de ensino.

Ao cristalizar o aluno como deficiente e incapaz, contribuindo para sua constituição como um indivíduo deficiente, a escola não o irá proteger, como ela própria imagina, mas, sim, manter imagens estereotipadas que geram preconceito e exclusão, e que estão fundadas na própria imagem que o aluno com deficiência vem construindo sobre si mesmo.

Essa pesquisa constatou que os processos de inclusão escolar são viáveis, mas merecem um olhar cuidadoso para as práticas e para as relações que se estabelecem no cotidiano escolar, em relação ao aluno com deficiência mental. A inclusão escolar desses alunos não se restringe a ocupar um espaço na sala de aula. Ela implica um processo de ressignificação da deficiência e do lugar que esse indivíduo ocupa na sociedade.

Nesse trabalho de pesquisa, a deficiência mental é concebida como uma condição e a inclusão como um processo que pressupõe aceitar o diferente sem estigmatizá-lo como menor, sem torná-lo normal/igual. Eessa transformação exige um outro contato, um outro tipo de comportamento, de auxílio mútuo, pressupondo que cada indivíduo seja diferente, que a diversidade exista e que possamos conviver com ela.

A transformação não pode ser compreendida apenas como uma transformação do ambiente, mas também do indivíduo com deficiência que precisa ressignificar sua prática, sendo capaz de utilizar a sua atividade de forma mais significativa e criativa.

Na teoria winnicottiana, o ser humano é um ser de relação, e é na relação com outro ser humano que se possibilitam as mudanças. A partir de uma experiência de relação baseada na confiabilidade, procurou-se oferecer outros modelos de relação entre os alunos, objetivando favorecer, através da atividade lúdica, essas relações.

A escolha da atividade lúdica deve ser entendida por ser uma atividade da infância. É na infância que ela se inaugura. Além disso, parto do pressuposto que a atividade deva ser tratada e pensada de forma mais 
ampla, isto é, menos como atividade determinada, mas como uma qualidade de relação que o indivíduo estabelece com os objetos do mundo externo e a conseqüente apropriação da experiência cultural. Como atividade humana, abre possibilidades para um campo onde as subjetividades se encontram com os elementos da realidade externa, possibilitando uma experiência criativa com o conhecimento.

As atividades realizadas partiam de alguns princípios: o primeiro é que a atividade, como ação significativa e potencializadora de um ato criativo, sustentada em uma relação de confiabilidade, permitiria que a expressão cultural de cada criança pudesse dialogar e construir um campo compartilhado, possibilitando a interação entre os indivíduos envolvidos.

O segundo princípio se refere aos jogos em grupo, que propiciariam a cooperação a partir de suas regras, isto é, as regras do jogo são de colaboração, pois o jogo não pode ser jogado a não ser que todos os jogadores concordem, mutuamente, com as regras e que as sigam, cooperando.

Construir um ambiente lúdico, que propicie relações menos individualizadas e mais coletivas, onde a autonomia possa contribuir para gerar relações solidárias e contribua para a formação de uma outra cultura, parece ser uma alternativa para o processo de inserção/inclusão desses alunos no âmbito escolar.

\section{Referências}

Amiralian, M. L. T. M. (2003). A clínica do amadurecimento e 0 atendimento às pessoas com deficiências. Natureza Humana, 5 (1), 205-219.

Bueno, J. G. S. (1999). Educação especial brasileira: integração/segregação do aluno diferente (pp.15-53). São Paulo: Educ.
Ezpeletta, J., \& Rockwell, E. (1989). Pesquisa participante (pp.74-120). São Paulo: Cortez.

Freller, C. C. (1999). Pensando com Winnicott sobre alguns aspectos relevantes ao processo de ensino e aprendizagem. Revista de Psicologia USP, 10 (2), 189-203.

Jerusalinsky, A., et al. (1999). Psicanálise e desenvolvimento infantil. Porto Alegre: Artes e Ofícios.

Jordão, M. C. M. (2001). A criança, a deficiência e a escola: uma intervenção orientada pela psicanálise. Dissertação não-publicada, Instituto de Psicologia, Universidade de São Paulo.

Jurdi, A. P. S (2004). O processo de inclusão escolar do aluno com deficiência mental: a atuação do terapeuta ocupacional. Dissertação não-publicada, Instituto de Psicologia, Universidade de São Paulo.

Kupfer, M. C., Cufaro, A. C., Boudard, B., Baratto, G., Mena, L. F. B., Pavone, S., Leão, S. C., Magalhães, S. C., Mariage, V., Sayão, Y., Rafaeli, Y. M., \& Vanderveken, Y. (Orgs.). (2000). Tratamento e escolarização de crianças com distúrbios globais de desenvolvimento (pp.89-99). São Paulo: Ágalma.

Mazzotta, M. J. S., \& Sousa, S. M. Z. (2000). Inclusão escolar e educação especial: considerações sobre a política educacional brasileira. Estilos da Clínica, 5 (9), 96-108.

Mittler, P. (2003). Educação inclusiva: contextos sociais (pp.23-96). São Paulo: Artmed.

Rosa, S. S. (1996). A dissociação do self e suas implicações na educação. Revista Percurso, 17 (2), 75-83.

Winnicott, D. W. (1975). Objetos transicionais e fenômenos transicionais. In O brincar e a realidade (pp.13-44). Rio de Janeiro: Imago.

Winnicott, D. W. (1983). Moral e educação. In O ambiente e os processos de maturação (pp.88-98). Porto Alegre: Artes Médicas.

Winnicott, D. W. (1990). Natureza humana (pp.25-180). Rio de Janeiro: Imago.

Winnicott, D. W. (1999). O aprendizado infantil. In Tudo começa em casa (pp.137-144). São Paulo: Martins Fontes.

Winnicott, D. W. (2000). A mente e sua relação com o psicossoma (pp.409-425). In Da pediatria à psicanálise. Rio de Janeiro: Imago.

Recebido em: 27/9/2005

Versão final reapresentada em: 14/12/2005

Aprovado em: 17/1/2006 